\title{
Classroom Management in Schools
}

\author{
- Chanakya P. Rijal
}

\begin{abstract}
Among the various concepts emerged more recently in the field of formal education, especially in school education, classroom management has been considered as one of the integrated functions of institutional and functional intervention areas in teaching-learning. In this discourse, different professionals and institutions happen to proclaim different strategies and functional inputs so as to transform classroom as one of the most essential areas of school transformation. The scope of functional coverage of classroom management has expanded significantly these days from the concept of traditional physical structural shape to induction of newer approaches of student participation, learner focused teaching learning, collaborative and cooperative approaches to teaching-learning materials development and implementation, making classroom discourses more socio-ethically sound, and creating appealing classroom infrastructure and rules for teachers, students and also for the parents. In fact, there is no readymade capsule to swallow as the final solution for this issue and there is also no final destiny as the overall concept of classroom and its arrangement has been consistently overhauled globally.
\end{abstract}

Key words: Classroom management, collaborative learning, effective classroom, learner-centered classroom management, total quality management (TQM) in education.

\section{Preamble}

It has been well said that we must show adequate love, care and compassion for our students, and in return, they will show it towards others. This is all about chain effect in collaborative learning and transformation system. More importantly, it is the core expected value of education today. For this, our classrooms must be appealing, inviting and luring enough to impart an effective collaborative learning exchange. The classroom's physical as well as behavioral structural sets and overall operating system applied will confirm the direction and intensity of each learner's behavior. Effective classroom management is universally considered as one of the indicator for measuring the teacher effectiveness too. More importantly, it has been considered as an integral function of quality school management which includes total participation, learner focused approaches of teaching learning, shared commitment, system standardization and measurement, and continuous improvement of everything that the school does (Rijal, 2011; Everston, \& Neal, 2006). 
In a scholarly work on classroom management, two scholars (Everston, \& Neal, 2006) have contributed with as many as four basic principles as the foundation in course of reforming the idea of managing classrooms in schools. These scholars have emphasized on establishing a shared conceptualization of a more dynamic classroom approach as the first step of this noble job, followed by the creation of learning-centered classroom environment, and then redefining the classroom structural system and finally establishing a robust mechanism for measuring the outcomes of implementation of each intervention. Such idea has been quite similar to that of Rijal (2004), who intends to convey the significance of systems approach to education.

According these scholars, conceptualization of learning needs from the view points of academic, moral and social aspects, in addition with integration of management and instructional systems forms a basis or foundation to go ahead in the mission to reform classroom system. The creation of learning-centered environment in the classroom has to be emphasized with adequate focus on creating flexible room arrangements, forming different social forums within the members of the class, arranging multiple information resources, and planning with fluid and effective use of time. Similarly, in the course of redefining the classroom, adequate focus should be on building the whole classroom as a learning community with adequate backing by robust norms and rules. Also, there should be evidence for the provision of shared responsibility. Finally, the makers of effective classroom arrangements also must focus on creating and implementing effective benchmarks to measure the outcomes of each intervention time and again in each cycle of performance
(Everston, \& Neal, 2006).

Candler (2014) shares:

I guess what I like to do best is find the most powerful teaching strategies and make them easy to implement. I'm currently taking a year off from the classroom so I can create more resources and learn more about how to use technology in the classroom.,

The makers of effective classrooms should love to teach and spend significant amount of time in writing books and developing a collection of teaching materials. And more importantly, the teaching styles should include many active engagement strategies such as cooperative learning, interactive whiteboard use, and learning centers. On top of all, the teacher should have a passion for sharing those types of lessons with other teachers (Rijal, 2004).

From a more recent work of Emmer and Evertson (2012), the present scholar would like to deduct a procedural system of functions covering the entire job of classroom managementas -1 . organize the classroom materials, 2. make a choice over rules and procedures, 3. manage strategically and effectively the work of the students as a collaborative mission, 4. commence everything with a good start, 5. expose effectiveness in planning and executing lessons, 6. help students develop and manage cooperative learning groups within the class membership, 7. Transform and maintain more conducive student behavior, 8 . Empower the entire teaching-learning community with effective communication skills, 9. manage effectively and timely the problematic behaviors as and when they appear to take place or even before, and 10. Manage with priority 
the special learner groups, who otherwise, may not learn effectively.

\section{Rationale of the study}

The idea of writing this article as a link to promoting essential learning about classroom management came in existence in response to current need of reforming our overall classroom approaches, tools and infrastructure in managing classroom discourses as means of human transformation for life as well as national prestige in school education and instructional practices.

\section{Methodology}

As part of qualitative exploration, the present work has been solely based on exploration from existing literature. For this, extensive review of literature was performed and essential inputs were produced as part of inductive exploration within qualitative paradigm of work. Such a work must come in a more expanded form in the days to come.

\section{Why classroom management?}

Management of any component in teachinglearning system may have varied purposes, but there should be a single primary reason of doing so. That is - enhancing the students' learning. Thus, effective classroom management should also be initiated with a common purpose to enhance the level of learning among the students, at any level, everywhere.

Lakes and Smith (2002) have recognized the significance of effective classroom management as the first tool to improve learning effectiveness. These scholars have suggested that classroom management should be considered as an integrated function of characteristics development in teachers, behavioral management across the school community, managing school environment for effective teaching-learning, organizing and managing resources for effective learning, and designing effective lessons for effective student learning whereby they could show up their optimal participation and process engagement. Of course, classroom management stands for managing effective teaching learning.

These scholars have claimed that effective classroom management has a noble reason of doing all of the things that a teacher does to organize students, space, time and materials so that instruction in content and student learning can take place by fostering student involvement and cooperation in all classroom activities, and establishing a productive working environment.

\section{Who is to take the responsibility?}

Miller (2012) has noted:

As educators, we are always looking for management strategies to try in the classroom. Note I said 'strategies', not the 'solutions.' When picking strategies, we have to know that because they are strategies, some may not work. But we can still build our toolkit so that we have something to try in any context.

This scholar agrees that there is a larger, more important issue to consider before venturing into management strategies to solve a problem in the classroom, that is students' engagement and as per this scholar, the best strategy for management issues is engaging curriculum and instruction. When I experience frequent management issues in my classroom, I first look to myself: "What is my role in creating this situation? Why are my students not engaged? I ask", says Miller (2012). It means that the teachers are the most responsible agency for creating the key issues in classrooms as well as resolving them. 


\section{How to do it, then?}

As suggested by Miller (2012), providing with autonomy, mastery of working with stuff, having defined a shared purpose with the students, and being focused on how to engage students in their works would work as good as other golden rules suggested by numerous scholars having interest of this field. That's all, not a big deal, in fact!

If one wants the students be engaged, he or she must facilitate with self-directed activities and learning models whereby the students are encouraged to take ownership of their work, with ample self-direction by flipping the classroom, differentiating instruction and using other best practices brought forth by other colleagues. There must be enough spaces in the classroom where students can direct their own learning. For this, a number of strategies may be used - use of goal setting sheets, logs, reflection, and planning forms can hold students accountable to the learning, while still allowing them autonomy to work the way they expect for themselves.

It is equally important to promote the students with their liking in getting better at stuff collection - skills, knowledge of content, and the like that they want to master at. However, during a strategically managed class a teacher should let students see the process of improvement. To engage students in mastery, a teacher has to create rubrics that show the progress from novice to master. A number of quality indicators can be created for those objectives that students can understand, and the teacher also should reward students for their work with performance and public celebration (Miller, 2012).
Through the collective efforts, the students need to find purpose in their work, and the teachers need to create authentic contexts, tasks, and audiences for their effective works. The focus should be creating the units or projects that have an authentic purpose and audience. Students may or may not do things for the teacher, but when experts are part of the process and product, they will engage in the work because it matters as the students normally create products that have real impact in learning and life, at large. Use of principles of the flat classroom to collaborate with classrooms across the world to solve problems together will result in with possibilities for purposeful and endless work at schools, suggests Miller (2012). Miller finally claims:

As you start your new school year, find ways to create spaces where students have autonomy, pursue mastery, and engage in tasks that have meaning. Start small at first, because as it may be challenging for you as the teacher, it may be the same for students. Often, students are disempowered in their learning and do not have the opportunity to engage in these three strategies for engagement. Empower your students by focusing on engagement, and the management issues will dissipate.

The Nepalese teachers can get a big lesson out of this discourse as the children are quite often made deprived of having their say or role.

In fact, the idea of 'classroom management' is all about creating a positive process climate and structural system in the class to confirm better learning, and thus, it should be considered as one of the standard-based requirements for effective teaching-learning as part of universal 
discourse. A scholar, in a more recent work entitled 'creating a climate for learning', has cited from the works of Miller (2012; as cited in Starr, 2014) that the most important action an effective teacher takes at the beginning of the year is creating a climate for learning.

In fact, Miller, has suggested as many as twelve steps for the teachers to make their classrooms more effective. These steps include -1 . develop a set of written expectations you can live with and enforce, 2. be consistent, always, 3. be patient with yourself and with your students, 4 . make parents your allies; call early and often; use the word "concerned"; when communicating a concern, be specific and descriptive, 5. Do not talk too much; use the first 15 minutes of class for lectures or presentations, then get the kids working, 6 . break the class period into two or three different activities; be sure each activity segues smoothly into the next, 7 . begin at the very beginning of each class period and end at the very end, 8. do not roll call; take the roll with your seating chart while students are working, 9. keep all students actively involved; for example, while a student does a presentation, involve the other students in evaluating it, 10 . discipline individual students quietly and privately; never engage in a disciplinary conversation across the room, 11. keep your sense of perspective and your sense of humor, and 12. know when to ask for help.

\section{Student-centered classrooms}

Evertson and Neal (2014) have worked on learning-centered classrooms and figured out a number of implications for classroom management in a more recent working paper and have revealed the changing roles of educational practices and policies to revamp the classrooms and schools to close the achievement gaps and promote excellence in learning for all students. These scholars have attempted to examine the best practices that shift classroom management emphases from controlling student behavior to creating learning-centered classrooms to foster the students' engagement, autonomy, and sense of being in an intact community by giving them progressively more responsibility, under the teacher's careful guidance. These scholars have further claimed such practices as part of school's instructional strategies aimed at helping students achieve high academic, moral, and social goals.

\section{Making a whole collaborative class (CL)}

Further, Candler (2014) has stated that before involving the students in cooperative learning activities or other active engagement lessons, it requires to establish clear procedures for whole class management and where effective management strategies are in place, both teachers and students can relax and enjoy the learning environment. In this discourse, Laura (2014) emphasizes on establishing procedures as the means of good classroom management through effective cooperative learning. This scholar has stressed that the schools and teachers need to have clearly defined set of procedures so that the children know the shared expectations and perform accordingly.

Similarly, Candler (2014) added implementation of a full-proof quiet signal as another strategy in classroom management to actively involve the students in the process of instruction. This scholar has identified a number of signaling strategies that include hand signal, bell signal, clicker, or even a rain-stick - all the means for getting the students' attention within very short span of time, say, in 3 to 5 seconds. Such signals should be something that can be used over and over without annoying the teacher as well as 
students. According to this scholar, all such signals must sound and seem quiet and favorite as well as perceived to be right for their use. They should sound pleasant but should easily be audible for all students.

Another equally effective strategy to be used in classroom management is to create sound classroom rules that rationally govern the behavior of the students and teachers. For instance, Candler (2014) has stressed the need for creating classroom rules to effectively and actively involve the entire class in establishing such rules for confirming a greater extent of students' ownership and shared commitment while implementing such rules in action. The present author has observed a great deal of success in Edify International School in Kathmandu where the teachers allow the children to develop their class rules by their own and the students are found to be quite enthusiastic in implementing and monitoring the effective implementation of such rules. In fact, a collaborative approach allows the students come forward with their creative ideas in managing their classrooms in a better way (Rijal, 2010).

In fact, managing a classroom means making teacher and students more active, collaborative and at the same time, more responsible for better learning, better learning for life (Rijal, 2011). Though the job seems quite simple on its surface, it is quite a technical aspect and requires a lot of techno-socially sound approaches to execute such a job. In this respect, different scholars have shared with different views on how to accomplish this job. For example, Candler (2014) has suggested with a three step process to make superfluous learning happen in the classroom, with specific attention on making sentence writing a fun-sum work in classrooms in early grades.
In the first step, this scholar suggests the respective teachers to craft mini-lessons on sentences, fragments, and run-ons by tactfully and joyfully combining a subject and a predicate while composing sentences and allowing the children to work on their own in the same pattern. The step two is about applying a collaborative mini-lesson to revise and expand the sentences following the sample works by the teacher and then the groups. For this, it requires a whole class modeling onto given assignment. Further, the same assignment may be expanded to cooperative learning or small group activity by allowing themselves to work freely on their own to go on creating a few base sentences and then continue expanding. The process also may include activity directions and question cards to prompt students as they are creating their new sentences.

As a reflection of this idea, our schools in Nepal can implement this method in making the class teachers and students work together to work on annual planning and preparation of classroom yearbook, preparation of classmate telephone directory, classmate birthday chart, etc. This all, if executed effectively, of course, will make classroom a beautiful place to work for all.

Sometimes, bringing parents upto the classroom and making them a part of classroom delivery when issues related to life skills, social sensitivity of the children, and so on are of subject matter of discussion. It requires a firm school policy appealing for the parents to turn around when their presence is required. Unfortunately, not all schools in Nepal have a vision in this respect (Rijal, 2009).

Cohen (1986) has worked on moving beyond the general question of effectiveness or productivity of small group learning with ample 
focus on various features of cooperative learning as well as studies of the relationship of interaction in small groups to outcomes. The scholar has attempted to critically analyze and develop propositions concerning the kinds of discourse that are productive of different types of learning as well as propositions concerning how desirable kinds of interaction may be fostered.

According to this scholar, limited exchange of information and explanation are adequate for routine learning in collaborative seatwork, whereas more open exchange and elaborated discussion are necessary for conceptual learning with group tasks and ill-structured problems. "Moreover, task instructions, student preparation, and the nature of the teacher role that are eminently suitable for supporting interaction in more routine learning tasks may result in unduly constraining the discussion in less structured tasks where the objective is conceptual learning", suggested Cohen (1986) with a claim that it is necessary to treat problems of status within small groups engaged in group tasks with ill-structured problems whereby the students are communicated with corresponding rewards that they are likely to get after each attainment, to guarantee better collaboration and higher performance.

\section{Cultural sensitivity and classroom management}

Weinstein, Clarke, and Curran (2013), on their work entitled, 'toward a conception of culturally responsive classroom management, have stressed on the issues related to socio-ethical and cultural aspects linked with classroom management. These scholars have pointed that given the increasing diversity of the classrooms; a lack of multicultural competence can exacerbate the difficulties that novice teachers have with classroom management.

According to these scholars, the definitions and expectations of appropriate behavior are often culturally influenced, and conflicts are likely to occur when teachers and students come from different cultural backgrounds. Further, these scholars have provided with a conception in this regard with five essential components -1 . recognition of one's own ethnocentrism, 2. having adequate knowledge of students' cultural backgrounds, 3. understanding of the broader social, economic, and political context around the school community, 4. capacitating the teachers with ability and willingness to use culturally appropriate management strategies, and 5.promoting a shared commitment to building caring classrooms.

\section{Conclusions and suggestions for implications in schools}

The present scenario confirms that 'classroom management' has emerged as a global issue, challenge as well as a rewarding prospect for high performing teachers, students and the administrators of educational institutions. Conceptually speaking, classroom management refers to a holistic managerial approach to transforming classrooms into more effective learning centers. And, thus, its functional coverage today cannot be limited to just managing physical infrastructure. Rather in includes effective management of collaboration, transforming school rules and regulations, capacitating both teacher and students, bringing ethics to classroom life, and making it a collective mission of all stakeholders sharing the interests and obligations.

Finally, based on overall reflexive and experiential learning, the present scholar would 
like to suggest for the application of these approaches in transforming the classrooms today:

1. Apply the 'assertive approach' to classroom management by specifying the rules of behaviour and consequences for failing in complying them.

2. Induce a 'business approach' managing academic institutions, however its endpurpose is the human transformation; it is quite essential to measure the systems' effectiveness at all levels inputs, processes, outputs, outcomes and broader impacts. Communication of resources, procedures and expected results would hopefully bring in positive results.

3. Application of 'behavioural modification approach' should be widely recognized at both student as well as teacher level to transform personality and institutional image through the creation of better learning opportunities aiming one's socio-psychological, biological, and cognitive transformation. Classroom should be promoted as an effective laboratory to do all this.

4. As part of 'group managerial approach' team work must be induced as a means of achieving collaborative and cooperative learning for life.

5. The teachers must be educated how to develop and execute 'group guidance approach' in classroom management so as to bring in quicker and more effective results.

6. Our classrooms must be transformed as such that there must be a sense of execution of 'acceptance approach' in classroom management and entire teaching learning philosophy of schools.

7. The execution of 'success approach' recognizes mass rewards, appreciation, and promotion of a culture of celebration of each success more collectively.

\section{About the author \\ Chanakya P. Rijal holds a Ph D degree in Educational Leadership from Kathmandu University, Nepal after obtaining an MBA degree from Maastricht School of Management, The Netherlands. He has earned several diplomas from different institutions with specialization in corporate communications, institutional governance, computing, strategic thinking, and teaching pedagogies. In a career span of about 25 years, he has gained extensive experience of establishing and promoting a number of successful education institutions in Nepal. He is also Life Member of NELTA. He can be visited at: rijalcpr@gmail.com, and www.slideshare.net/rijalcpr.}

\section{References}

Candler, L. (2014). Whole class management tips: teaching resources. Available at: h t t p : / / w w w . l a u r a c a d l e r. com/strategies/classmanage.php. Retrieved on: November 18, 2014.

Cohen, E. G. (1986). Restructuring the Classroom: Conditions for Productive Small Groups. Stanford University.

Emmer, E. T., \& Evertson, C. M. (2012). Teach a book: classroom management formiddle and high school teachers. Amazon.com. Available at: http://www.amazon.com/classroom- 


\section{Classroom Management in Schools}

management-middle-teachers-edition. Retrieved on: November, 21, 2014.

Evertson, C. M., \& Neal, K. W. (2014). Looking into learning-centered classrooms: implications for classroom management.A working paper of National Education Association Research Department.Washington DC. Available at: http://www.nea.org. Retrieved on: November 18, 2014.

Evertson, C. M., \& Neal, K. W. (2006). Looking into learning-centered classrooms: implications for classroom management. Classroom Management. July 2006. Atlanta, GA: National Education Association [NEA].

Lakes, K., \& Smith, L. (2002). Classroom management for effective instruction. Proceedings of a seminar on Effective Classroom management. October, 2002.

Miller, A. (2012). From management to engagement. Edutopia. Available at: http://www.edutopia.org/blog/classro om-management-student-engagementandrew-miller. Retrieved on: November 20, 2014.

Rijal, C. P. (2011). Leadership readiness: road to TQM implementation. Germany: Lambert Academic Publishing. (2010). Edify approach to quality school education. Kathmandu: Edify International School. (2009). Instructional leadership in classrooms. Classroom management workshop proceedings, Edify International, Kathmandu, April 7, 2009. (2004). Leadership readiness to implement total quality management in the Nepalese secondary schools. An unpublished doctoral research dissertation. Kathmandu: Kathmandu University, School of Education.

Starr, L. (2014). Creating a climate for learning. Available at: http://www.educationworld. com/a_curr/curr155.shtml. Retrieved on November 19, 2014.

Weinstein, C. S., Clarke, S. T. , \& Curran, M. (2013). Toward a Conception of Culturally Responsive Classroom Management. Journal of Teacher Education. Available at: http://jte. sagepub.com/content/55/1/25. short. Retrieved on: November 20, 2014. 